\title{
Crystal structure and spectral of new hydrazine-pyran-dione derivative: DFT enol $\leftrightarrow$ hydrazone tautomerization via zwitterionic intermediate, hirshfeld analysis and optical activity studies
}

\author{
Abdenour Guerraoui a , Amel Djedouani b, c, *, Erwann Jeanneau ${ }^{\text {d }}$, Abdecharif Boumaza ${ }^{\text {, }}$ \\ Ali Alsalme ${ }^{\mathrm{f}}$, Abdelkader Zarrouk ${ }^{g}$, Kifah S.M. Salih ${ }^{\mathrm{h}}$, Ismail Warad ${ }^{\mathrm{h},{ }^{* *}}$ \\ ${ }^{a}$ Department of Material Science, Faculty of Science and Technology, University of Abbes Laghrour, Khenchela, 40000, Algeria \\ ${ }^{\mathrm{b}}$ Laboratory of Analytical Physicochemistry and Crystallochemistry of Organometallic and Biomolecular Materials, UFMC1, 25000, Constantine, Algeria \\ c Université de Lyon, Centre de Diffractomètre Henri Longchambon, Villeurbanne, France \\ d Structural Properties and Interatomic Interactions Laboratory (LASPI) and Technology, University of Abbes Laghrour, Khenchela, 40000, Algeria \\ e Structural Properties and Interatomic Interactions Laboratory (LASPI) and Technology, University of Abbes Laghrour, Khenchela 40000, Algeria \\ ${ }^{f}$ Department of Chemistry, College of Science, King Saud University, P.O. Box 2455, Riyadh, 11451, Saudi Arabia \\ ${ }^{\mathrm{g}}$ Laboratory of Materials, Nanotechnology and Environment, Mohammed V University, Faculty of Sciences, 4Av. Ibn Battuta, PO B.P. 1014 Rabat, Morocco \\ ${ }^{\mathrm{h}}$ Department of Chemistry and Earth Sciences, College of Arts and Sciences, Qatar University, P. O. Box 2713, Doha, Qatar
}

\section{A R T I C L E I N F O}

\section{Article history:}

Received 15 May 2020

Received in revised form 14 June 2020

Accepted 17 June 2020

Available online 23 June 2020

\section{Keywords:}

Enol $\leftrightarrow$ hydrazinium

Crystal structures

DFT calculations

Hirshfeld surface

Optical

\begin{abstract}
A B S T R A C T
A novel functionalized Schiff base derivative, (E)-3-(1-(2-(9H-fluoren-9-ylidene)hydrazineyl)ethylidene)6-methyl-2H-pyran-2,4(3H)-dione, was synthesized via subsequent condensation/tautomerization processes in a high yield. The product was fully characterized using NMR, FT-IR, and single-crystal XRD; the results of DFT simulations were in respectable agreement with crystallographic data. To elucidate the isomerization, the enol $\leftrightarrow$ hydrazinium tautomerism has been pursued theoretically, suggesting an intramolecular single proton transfer (SPT) from enol $(\mathrm{O} \ldots \mathrm{H})$ to the closest $\mathrm{N}=\mathrm{C}$ unit, giving the hydrazine $(\mathrm{N}-\mathrm{H})$ via $\left[\mathrm{N}^{+}-\mathrm{H} \ldots . \mathrm{O}^{-}\right] \mathrm{S}(6)$ zwitterionic intermediate. The results of Hirshfeld surface analysis (HSA) and Molecular electronic potential (MEP) were matching the experimental XRD results. Since a number of hydrogen bonding groups, $\mathrm{C}-\mathrm{H} \ldots \pi$, and $\pi \ldots \pi$-stacking interactions were detected experimentally. The optical properties of the desired compound were experimentally and theoretically figure out.
\end{abstract}

() 2020 Elsevier B.V. All rights reserved.

\section{Introduction}

The enol-keto tautomerism has been receiving a high level of attention and consideration for being significant in broad fields of biochemistry and chemistry [1-3]. The investigation of proton transfer between two functional groups in the same compound, namely, excited-state intramolecular proton transfer (ESIPT) gives access to know about the physicochemical properties and biological activities of the examined molecules [4]. A number of factors could

\footnotetext{
* Corresponding author. Laboratory of Analytical Physicochemistry and Crystallochemistry of Organometallic and Biomolecular Materials, UFMC1, 25000, Constantine, Algeria.

** Corresponding author.

E-mail addresses: djedouani_amel@yahoo.fr (A. Djedouani), ismail.warad@qu. edu.qa (I. Warad).
}

influence the proton transfer equilibrium in favor of the predominantly stable species (the keto or the enol forms) such as hydrogen bond, solvents, physical state, temperature, light and inter- and intra-molecular forces [5].

The photophysical properties of ESIPT have been comprehensively explored and functionalized to a selection of applications in chemistry. Hence, molecules possessing the capability of ESIPT led to the development of novel materials for biosensing, chemical sensing, cell imaging, optoelectronics, probing of materials and white light LED [6]. ESIPT typically exists in an unparalleled fourlevel photochemical reaction mode, taking place in femtoseconds [4]. Over photoexcitation, the electronic charge of molecules can be reallocated, causing increased in the acidity of the $\mathrm{O}-\mathrm{H}$ or $\mathrm{N}-\mathrm{H}$ hydrogen bond donor groups and a greater level of basicity for the $\mathrm{H}$-bond acceptors like $\mathrm{C}=\mathrm{O}$ or $\mathrm{C}=\mathrm{N}$ in the enol form, giving rise to extremely rapid enol to keto tautomerization [3]. 
Numerous Schiff base functionalized compounds (SBFCs) have been synthesized since the first synthetic protocol disclosed in 1884 b y Hugo Schiff from the condensation of amines with ketones or aldehydes and utilized in potential implementations, including anticorrosive, nonlinear optical materials, anticancer medicines, optic data storage and coordination chemistry [7,8]. The thermochromism and photochromism are remarkable features can be displayed by the Schiff base (SB) functional groups in the solid state. These features are normally resulting from a proton-transfer from the o-hydroxyaryl group to the attached imine moiety [9]. Depending on the substitutions and the electronic conditions, the o-hydroxyaryl SB compounds could be present either in the keto form, enol form, keto/enol mixtures or scarcely in the zwitterionic form. The latter exhibits an ionic $\mathrm{N}^{+}-\mathrm{H}$.... $\mathrm{O}^{-}$hydrogen bonding, in which the neutral $\mathrm{N}-\mathrm{H}$ bond is typically shorter than ionic $\mathrm{N}^{+}-\mathrm{H}$ bond $[10,11,12,13,14,15,16]$.

In the context of traditional chemistry, facts deal with observation through the determination of properties of molecules and characterization of the structure, which have been the center of interest for the last several centuries. Nowadays, computational approaches are focusing much more on the function of molecules and support the chemical research to answer numerous crucial steps taking place in the chemical process, though it is predominantly not likely to monitor the active intermediate or transition states of reactions [17].

This article describes the synthesis, spectral and single crystal structure of (E)-3-(1-(2-(9H-fluoren-9-ylidene)hydrazineyl)ethylidene)-6-methyl-2H-pyran-2,4(3H)-dione. The compound represents an appropriate bidentate ligand for coordination with transition metal ions via $\mathrm{N}$ and $\mathrm{O}$ atoms. We have been exploring such ligands to examine their coordination mode with a selection of metal ions and to look for potential biological activities [11,18-24]. The synthesis of the target compound was performed via condensation of (9H-fluoren-9-ylidene)hydrazine with 3acetyl-4-hydroxy-6-methyl-2H pyran-2-one, followed by tautomerization process to reach to the stable structure. The product was proved by XRD-single crystal, NMR and FT-IR; the optimized geometrical structure was accomplished by B3LYP/DFT calculation [25-28]. Moreover, the intramolecular single proton transfer (SPT) process was suggested to explain the enol $\leftrightarrow$ hydrazinium isomerization. The optical activity were determined experimentally then compare theoretically.

\section{Experimental}

\subsection{Measurements and materials}

The FT-IR in the range of $500-4000 \mathrm{~cm}^{-1}$ was recorded in solid state (KBr disks) using a Shimadzu FTIR-8010 M spectrometer. The ${ }^{1} \mathrm{H}$ NMR spectrum was recorded in $\mathrm{CDCl}_{3}$ on Jeol GSX WB spectrometer at $270 \mathrm{MHz}$. All chemicals were purchased from different suppliers (Sigma-Aldrich, Acros, etc) and employed without any purification.

\subsection{Synthesis of desired $S B$}

9-Fluorenone hydrazone $(0.01 \mathrm{~mol})$ was dissolved in $15 \mathrm{~mL}$ of ethanol, then added to stirring dehydroacetic acid $(0.01 \mathrm{~mol})$ dissolved $30 \mathrm{~mL}$ of ethanol. The reaction mixture was subjected to reflux for an hour and the precipitate product was filtrated, washed with water and purified by crystallization from $\mathrm{ETOH} / \mathrm{H}_{2} \mathrm{O}$ to afford (E)-3-(1-(2-(9H-fluoren-9-ylidene)hydrazineyl)ethylidene)-6methyl-2H-pyran-2,4(3H)-dione, diffraction quality crystals in a good yield. ${ }^{1} \mathrm{H}$ NMR $\left(\mathrm{CDCl}_{3}\right): \delta_{\mathrm{H}}=2.15\left(\mathrm{~s}, 3 \mathrm{H}, \mathrm{CH}_{3}\right) ; 2.56(\mathrm{~s}, 3 \mathrm{H}$, acetyl- $\left.\mathrm{CH}_{3}\right) ; 5.91(\mathrm{~s}, 1 \mathrm{H}$, pyrone- $\mathrm{CH}) ; 7.20-7.90(\mathrm{~m}, 8 \mathrm{H}$, aromatic-
Table 1

Crystal structure refinement details of the synthesized compound.

\begin{tabular}{ll}
\hline Empirical formula & $\mathrm{C}_{21} \mathrm{H}_{16} \mathrm{~N}_{2} \mathrm{O}_{3}$ \\
\hline Formula weight, g/mol & 344.36 \\
CCDC & $2,004,993$ \\
Crystal color & Yellow \\
Space group & $\mathrm{P} 21 / \mathrm{c}$ \\
Crystal system & Monoclinic \\
$\mathrm{F}(000)$ & 552 \\
$\mathrm{a}, \mathrm{b}, \mathrm{c}(\AA)$ & $11.976(2), 5.0343(17), 26.710(7)$ \\
$\mathrm{V} /\left(\AA^{3}\right)$ & $1594.4(7)$ \\
$\mathrm{Z}$ & 4 \\
Temperature $/ \mathrm{K}$ & 100 \\
Radiation & Mo K $\alpha(\lambda=0.71073)$ \\
$\mathrm{D}_{\text {calcd }}\left(\mathrm{g} / \mathrm{cm}{ }^{3}\right)$ & 1.410 \\
$\mu\left(\mathrm{mm}{ }^{-1}\right)$ & 0.10 \\
Crystal size $(\mathrm{mm})$ & $0.62 \times 0.06 \times 0.04$ \\
$\mathrm{~T}_{\min }, \mathrm{T}_{\max }$ & $0.548,1.000$ \\
$\mathrm{R}[\mathrm{F} 2>2 \sigma(\mathrm{F} 2)]$ & 0.080 \\
$\mathrm{w} R(\mathrm{~F} 2)$ & 0.226 \\
Rint & 0.162 \\
$\Delta_{\rho \max }, \Delta_{\rho \min }\left(\mathrm{e} / \AA^{3}\right)$ & $0.41,-0.34$ \\
\hline
\end{tabular}

CH), 9.85 (b, 1H, N-H), IR (KBr) $\nu / \mathrm{cm}^{-1}: 1715,1653,1527,1314$, 1020, 845, 732, 644.

\subsection{XRD-analysis}

XRD-crystal data were recorded at $100 \mathrm{~K}$ by means of the CrysalisPro software [29] on a Gemini kappa-geometry diffractometer (Rigaku OD, 2018) equipped with an Atlas CCD detector and using Mo radiation $(\lambda=0.71073 \AA)$. The structure was solved with the SHELXT [30] structure solution program using the Intrinsic Phasing solution method and by using Olex2 [31]. The model was refined with version 2018/3 of SHELXL [32] using Least Squares Minimization. The crystal data and structure refinement parameters of the free ligand are illustrated in Table 1. All hydrogen atoms (except hydrogen atoms attached to $\mathrm{N}$ atom) were included in geometric positions. The hydrogen atoms bound to $\mathrm{N}$ atom was located in difference Fourier map and its coordinate was refined with displacement parameters. The final difference Fourier maps showed no peaks of chemical significance.

\subsection{Computational details}

Gaussian 09 W 32 bit software was served for all DFT operations in gaseous state at DFT/B3LYP method and $6-311++\mathrm{G}(\mathrm{d}, \mathrm{p})$ as basis set $[33,34]$. The HSA was carried out using Crystal Explorer 3.1 [35].

\section{Results and discussion}

\subsection{Synthesis and X-ray analysis}

The final product ((E)-3-(1-(2-(9H-fluoren-9-ylidene)hydrazineyl)ethylidene)-6-methyl-2H-pyran-2,4(3H)-dione) was synthesized via equimolar condensation of 3-acetyl-4-hydroxy-6-methyl2H-pyran-2-one with (9H-fluoren-9-ylidene)hydrazine in ethanol under reflux conditions, to initially provide the 4-hydroxy-pyran-2one derivative. Since the final product structure has been proved by XRD-analysis as pyran-2,4-dione (keto form) and not the expected product 4-hydroxy-pyran-2-one (enol form), therefore, the enolketo tautomerization process via the zwitterionic intermediate (Scheme 1) has been suggested [3-5].

Fig. 1 illustrates the XRD-analysis and confirming the molecular structure of the target compound, which was crystallized in Monoclinic, space group $P 2_{1} / c$ with the following lattice 


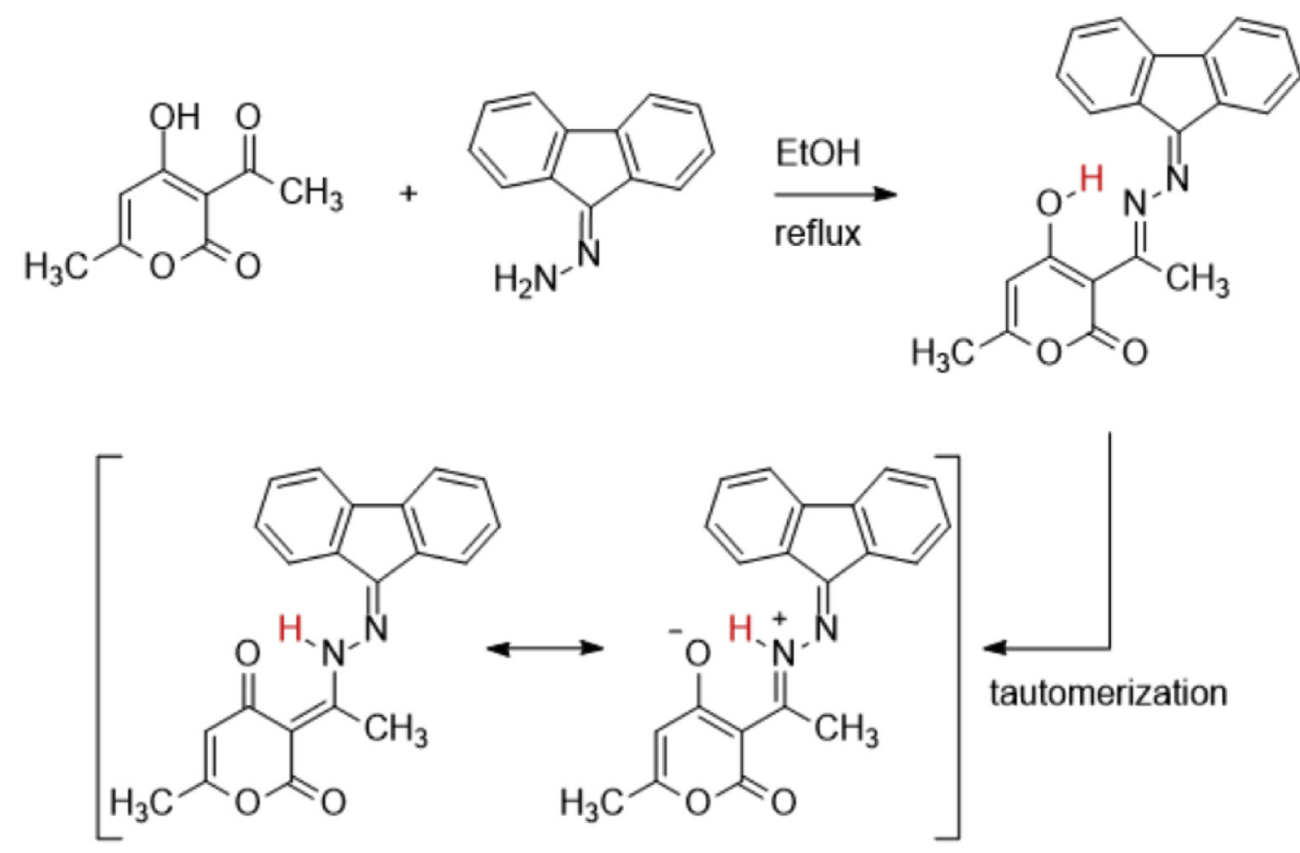

Scheme 1. Synthesis of pyran-2,4-dione derivative.

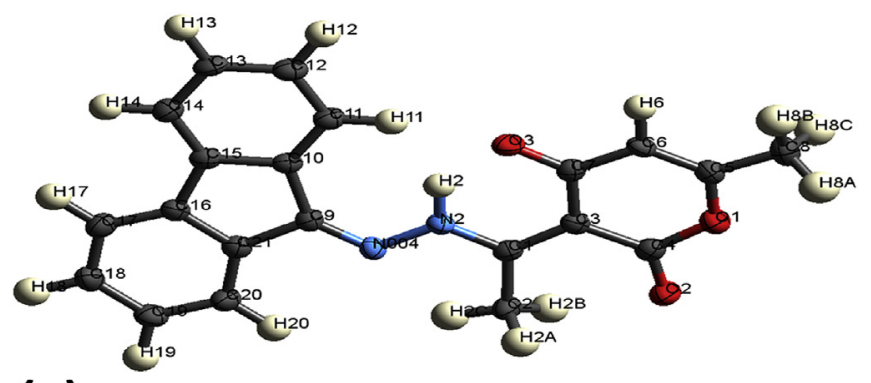

(a)

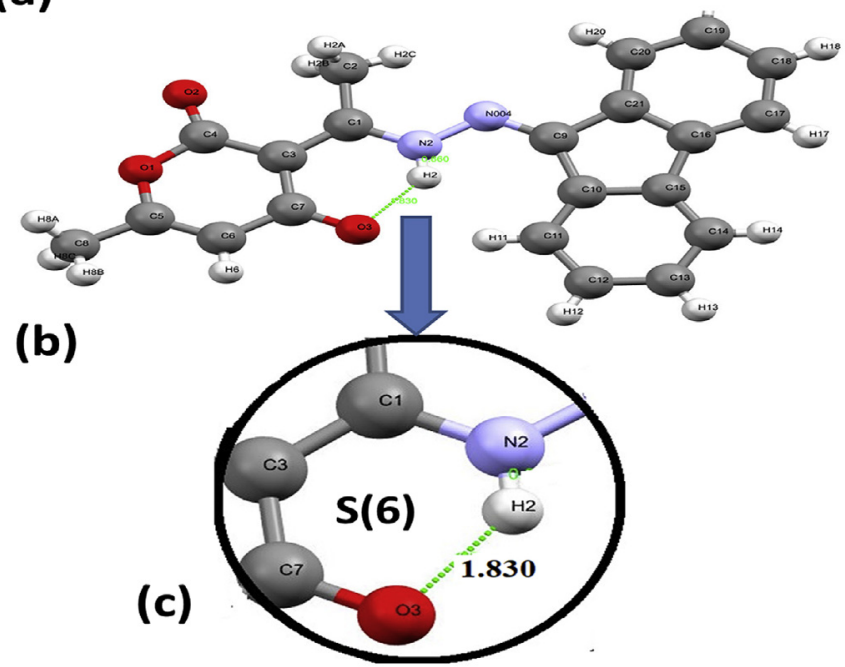

Fig. 1. Molecular structure of SB, (a) ORTEP diagram, (b) interHB and (c) S (6) motif.

parameters: $\mathrm{a}=11.976$ (2) $\AA, \mathrm{b}=5.0343$ (17), $\AA, \mathrm{c}=26.710$ (7) $\AA$, $\beta=98.06(2)^{\circ}$. The geometry of the double bond is confirmed as the E-isomer. The XRD outcomes have also proved the tautomerization, in which the proton of $\mathrm{OH}$ group in the enol-form has migrated to the close $\mathrm{N}$ of $\mathrm{N}=\mathrm{C}$ group. In the meantime, the $\mathrm{C}=\mathrm{O}$ and enamine groups were linked via a strong intramolecular $\mathrm{H}$-bond $[\mathrm{C}=\mathrm{O}$ ....H-N] with a distance of $1.830 \AA$, resulting a very stable $\mathrm{S}(6)$ ring motif (Fig. 1c). Such S (6) plays a critical role in stabilization of compound lattice. The carbon-nitrogen bond $=\mathrm{C} 1-\mathrm{N} 2$ found to be 1.340 (4) $\AA$, which agrees with $\mathrm{sp}^{3}$ hybridization of a single bond character of $\mathrm{N}$ and supported the $\mathrm{N}-\mathrm{H}$ bond formation [36].

The molecular lattice of the crystal reflects the presence of different types of short interactions, because of the presence of heteroatoms like $\mathrm{N}$ and $\mathrm{O}$, which play a decisive role in these interactions. The lattice displays 14 interactions as short contacts, four types of inter-forces are detected per molecule, four intermolecular H-bonds, two type of $\mathrm{C}=\mathrm{O} \ldots . . \mathrm{H}_{\mathrm{Ph}}$ with 2.619 (4) $\AA$ and another two of $\mathrm{H}_{\mathrm{Ph}} \ldots . \mathrm{O}=\mathrm{C}-\mathrm{O}$ with 2.628 (4) $\AA$ as displayed in Fig. 2a. Such links could resonate to the three-dimensional supramolecular network structure of the ligands. On the other hand, two non-covalent polar $\pi-\pi$ stacking interactions are noticed, corresponding to $\pi(\mathrm{C}=\mathrm{N}) \ldots . . \pi(\mathrm{O}-\mathrm{C}=\mathrm{O})$ with $3.239 \AA$ and $\pi(\mathrm{C}=\mathrm{N}) \ldots$. $\pi(\mathrm{C}=\mathrm{N})$ with $3.341 \AA$ distances, that attributed to the formation of layer-by-layer, Fig. 2b. Additional weak $\mathrm{H} \ldots . . \pi$ interactions were verified, two of the type $\mathrm{H}_{\mathrm{Me}} \pi(\mathrm{O}-\mathrm{C}=\mathrm{O})$ with $2.873 \AA$ and two of the type $\mathrm{H}_{\mathrm{Ph}} \ldots . \pi(\mathrm{Ph})$ with $2.832 \AA$ distances (Fig. 2c). Whereas, another two $\mathrm{H} \ldots . . \pi(2 \mathrm{C})$ interaction like $\mathrm{H}_{\mathrm{Me}} \ldots . \pi(2 \mathrm{C})$ with an average of about $2.710 \AA$, reflecting the formation of extra supramolecular interactions, as seen in Fig. 2 d.

\subsection{DFT structure analysis}

The three-dimensional arrangement of atoms was optimized (Fig. 3a) and compared with the obtained results of XRD. The selected experimental XRD and DFT outcomes of bond angle and bond length values are listed in Table 2. High level of agreement between XRD and DFT results is obvious in term of reliability factors. Graphical correlation of values of bond lengths and bond angles gave $\mathrm{R}^{2}=0.984$ and 0.990 , respectively, Fig. $3 c$ and e. Moreover, the experimental and simulated outcomes of bond length values are much closed to each other (Fig. 3b). This high agreement between the XRD and DFT results applies as well for all dihedral angles as represented in Fig. 3d. 

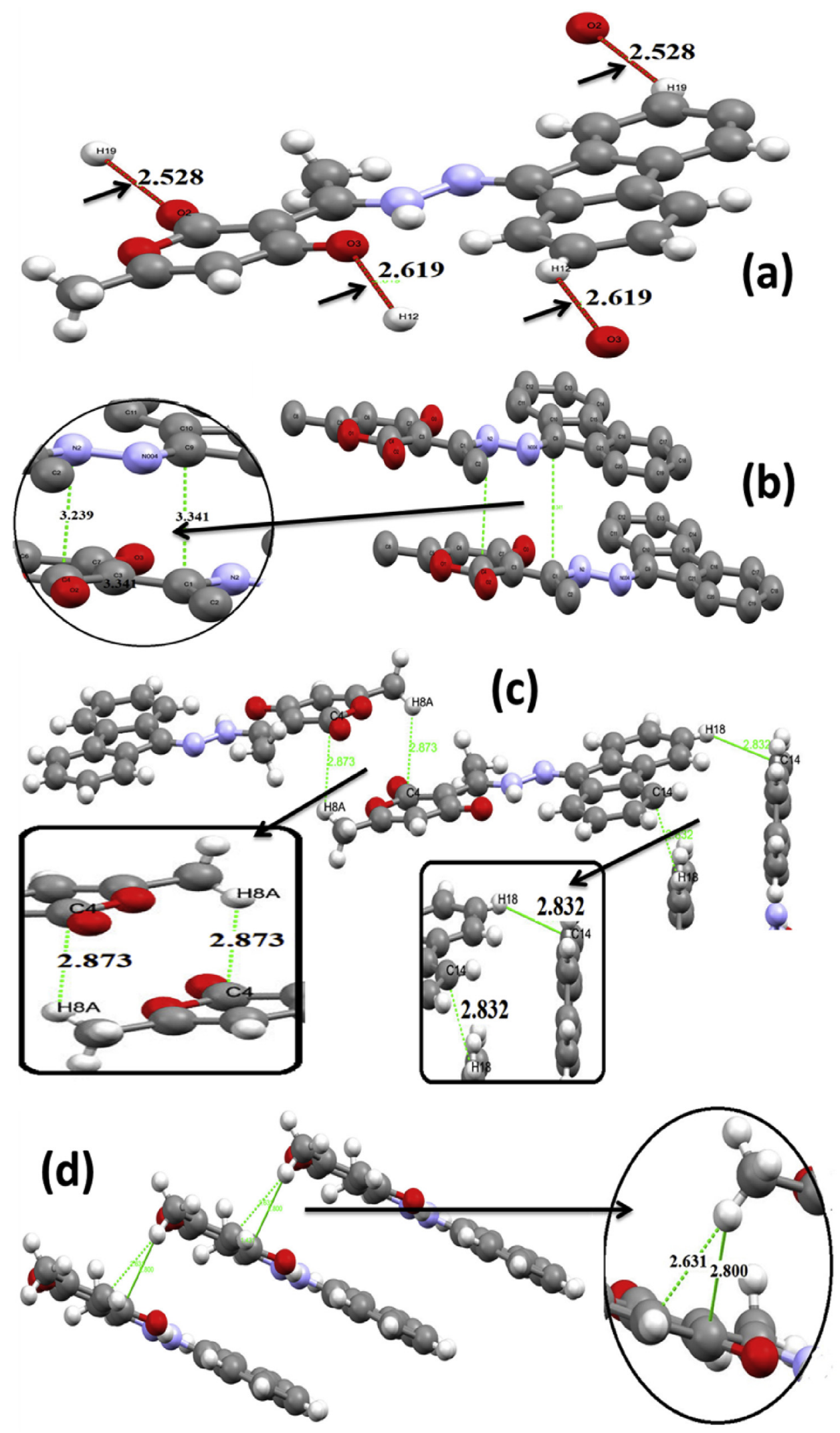

Fig. 2. Molecular interactions: (a) interHB, (b) $\pi$ - $\pi$ stacking, (c) $H_{P} \ldots . \pi(\mathrm{Ph})$ and (d) $H \ldots . \pi(2 \mathrm{C}$ ). 

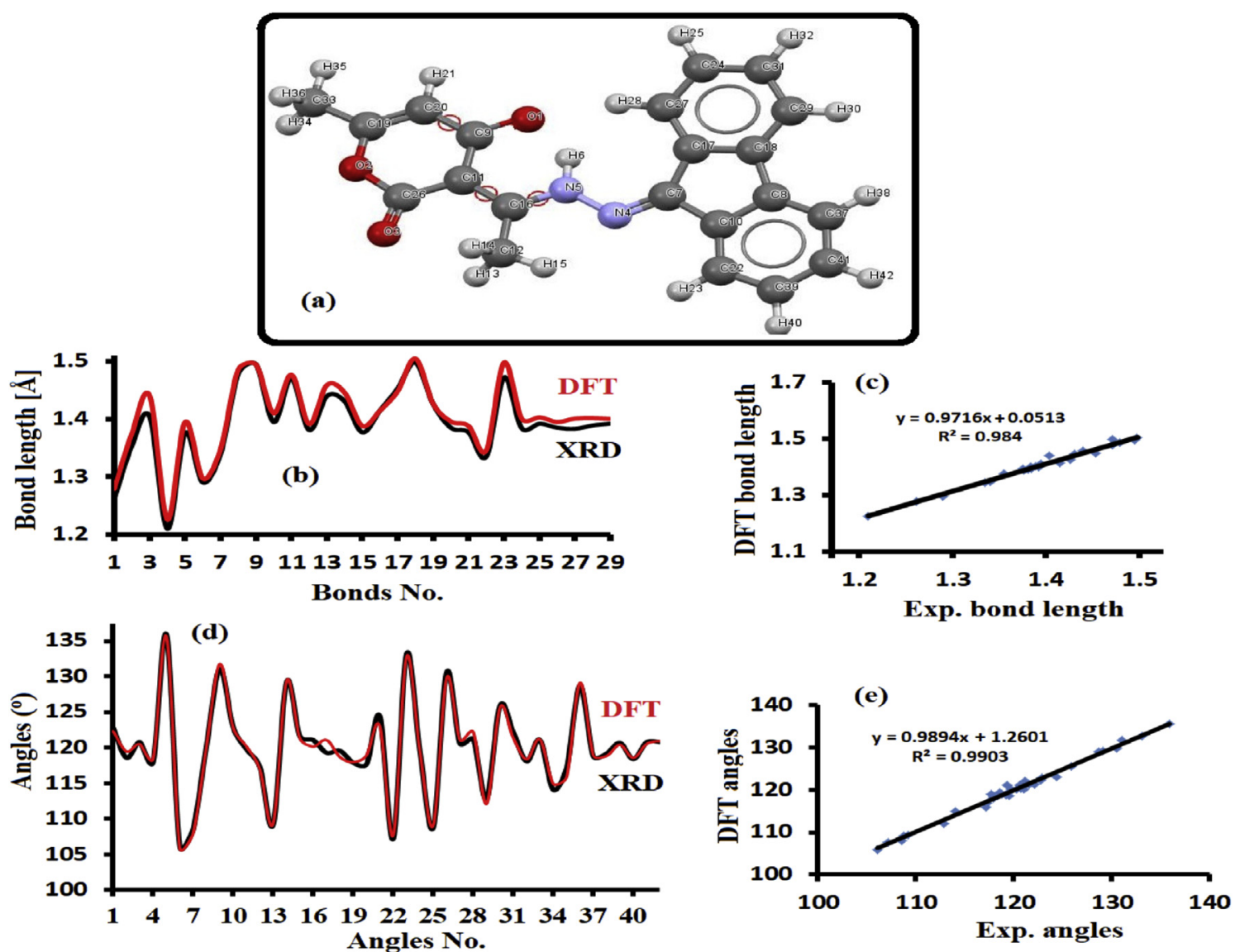

Fig. 3. DFT optimization structure (a). XRD/DFT histogram of bond lengths (b) and bond angles (d), DFT/XRD-graphical correlation for bond lengths (c) and bond angles (e).

Table 2

Selected DFT/XRD bond angles and bond lengths.

\begin{tabular}{|c|c|c|c|c|c|c|c|c|c|c|}
\hline \multirow[t]{2}{*}{ Bond No. } & \multirow{2}{*}{\multicolumn{2}{|c|}{ Bond type }} & \multicolumn{2}{|c|}{ Bond length $[\AA ̊]$} & \multirow[t]{2}{*}{ Angle No. } & \multirow{2}{*}{\multicolumn{2}{|c|}{ Angle type }} & & \multicolumn{2}{|c|}{ Angle value (o) } \\
\hline & & & XRD & DFT & & & & & XRD & DFT \\
\hline 1 & $\mathrm{O} 3$ & $\mathrm{C} 7$ & 1.262 & 1.279 & 1 & C5 & 01 & $\mathrm{C} 4$ & 122.8 & 122.3 \\
\hline 2 & 01 & $\mathrm{C} 5$ & 1.355 & 1.376 & 2 & N2 & N4 & C9 & 118.6 & 119.5 \\
\hline 3 & 01 & $\mathrm{C} 4$ & 1.404 & 1.440 & 3 & N4 & $\mathrm{N} 2$ & $\mathrm{C} 1$ & 120.8 & 120.6 \\
\hline 4 & $\mathrm{O} 2$ & $\mathrm{C} 4$ & 1.210 & 1.226 & 4 & N4 & C9 & $\mathrm{C} 21$ & 118.0 & 118.4 \\
\hline 5 & N4 & $\mathrm{N} 2$ & 1.376 & 1.395 & 5 & N4 & $\mathrm{C} 9$ & C10 & 135.9 & 135.6 \\
\hline 6 & N4 & C9 & 1.290 & 1.297 & 6 & $\mathrm{C} 21$ & C9 & C10 & 106.1 & 105.9 \\
\hline 7 & N2 & $\mathrm{C} 1$ & 1.340 & 1.347 & 7 & $\mathrm{C} 21$ & C16 & C15 & 108.6 & 108.0 \\
\hline 8 & C9 & $\mathrm{C} 21$ & 1.479 & 1.486 & 8 & $\mathrm{C} 21$ & C16 & $\mathrm{C} 17$ & 120.3 & 120.2 \\
\hline 9 & C9 & C10 & 1.495 & 1.495 & 9 & C15 & C16 & C17 & 131.1 & 131.8 \\
\hline 10 & C16 & $\mathrm{C} 21$ & 1.395 & 1.410 & 10 & $\mathrm{O} 3$ & $\mathrm{C} 7$ & C3 & 122.9 & 122.9 \\
\hline 11 & C16 & C15 & 1.471 & 1.477 & 11 & $\mathrm{O} 3$ & $\mathrm{C} 7$ & C6 & 119.8 & 120.2 \\
\hline 12 & C16 & C17 & 1.381 & 1.391 & 12 & $\mathrm{C} 3$ & $\mathrm{C} 7$ & C6 & 117.3 & 117.0 \\
\hline 13 & C7 & C3 & 1.440 & 1.459 & 13 & C9 & $\mathrm{C} 21$ & C16 & 109.2 & 109.3 \\
\hline 14 & C7 & C6 & 1.431 & 1.446 & 14 & C9 & C21 & C20 & 129.2 & 129.3 \\
\hline 15 & $\mathrm{C} 21$ & $\mathrm{C} 20$ & 1.377 & 1.388 & 15 & C16 & C21 & C20 & 121.6 & 121.4 \\
\hline 16 & C3 & $\mathrm{C} 1$ & 1.415 & 1.415 & 16 & C7 & $\mathrm{C} 3$ & $\mathrm{C} 1$ & 121.1 & 120.2 \\
\hline 17 & $\mathrm{C} 3$ & $\mathrm{C} 4$ & 1.453 & 1.449 & 17 & C7 & $\mathrm{C} 3$ & $\mathrm{C} 4$ & 119.3 & 121.1 \\
\hline 18 & $\mathrm{C} 2$ & C1 & 1.498 & 1.505 & 18 & $\mathrm{C} 1$ & C3 & C4 & 119.6 & 118.7 \\
\hline 19 & C10 & C15 & 1.426 & 1.427 & 19 & N2 & $\mathrm{C} 1$ & $\mathrm{C} 3$ & 117.9 & 118.0 \\
\hline 20 & C10 & C11 & 1.385 & 1.396 & 20 & N2 & $\mathrm{C} 1$ & $\mathrm{C} 2$ & 117.7 & 118.9 \\
\hline 21 & C15 & C14 & 1.377 & 1.388 & 21 & $\mathrm{C} 3$ & $\mathrm{C} 1$ & $\mathrm{C} 2$ & 124.4 & 123.1 \\
\hline 22 & C5 & C6 & 1.335 & 1.345 & 22 & C9 & C10 & C15 & 107.2 & 107.7 \\
\hline 23 & C5 & C8 & 1.472 & 1.498 & 23 & C9 & C10 & C11 & 133.2 & 132.8 \\
\hline 24 & $\mathrm{C} 20$ & C19 & 1.384 & 1.400 & 24 & C15 & C10 & C11 & 119.6 & 119.5 \\
\hline 25 & C12 & C11 & 1.392 & 1.403 & 25 & C16 & C15 & C10 & 108.8 & 109.1 \\
\hline 26 & C12 & C13 & 1.385 & 1.395 & 26 & C16 & C15 & C14 & 130.6 & 129.8 \\
\hline 27 & C14 & C13 & 1.383 & 1.401 & 27 & C10 & C15 & $\mathrm{C} 14$ & 120.6 & 121.1 \\
\hline 28 & C17 & C18 & 1.389 & 1.402 & 28 & 01 & C5 & C6 & 121.2 & 122.2 \\
\hline 29 & C19 & C18 & 1.392 & 1.400 & 29 & 01 & $\mathrm{C} 5$ & $\mathrm{C} 8$ & 112.9 & 112.1 \\
\hline
\end{tabular}



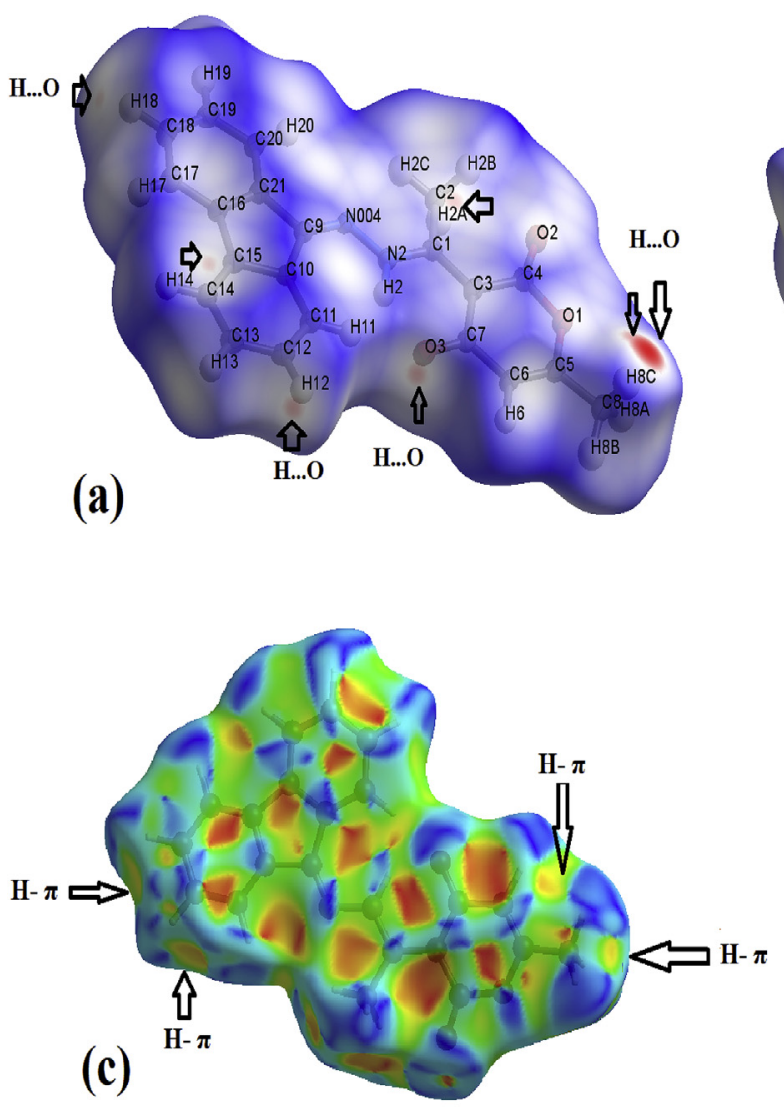

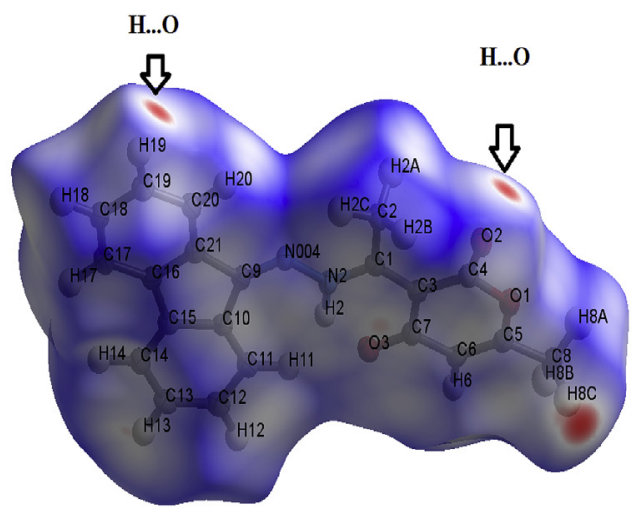

(b)

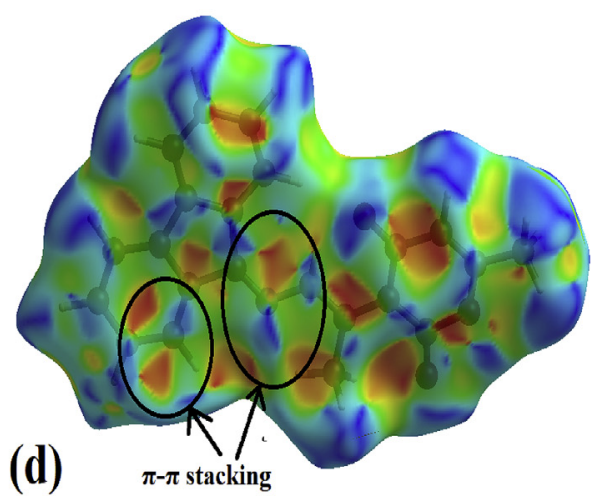

Fig. 4. Mapped $d_{\text {norm }}(\mathrm{a}-\mathrm{b})$ and shape index (c-d).

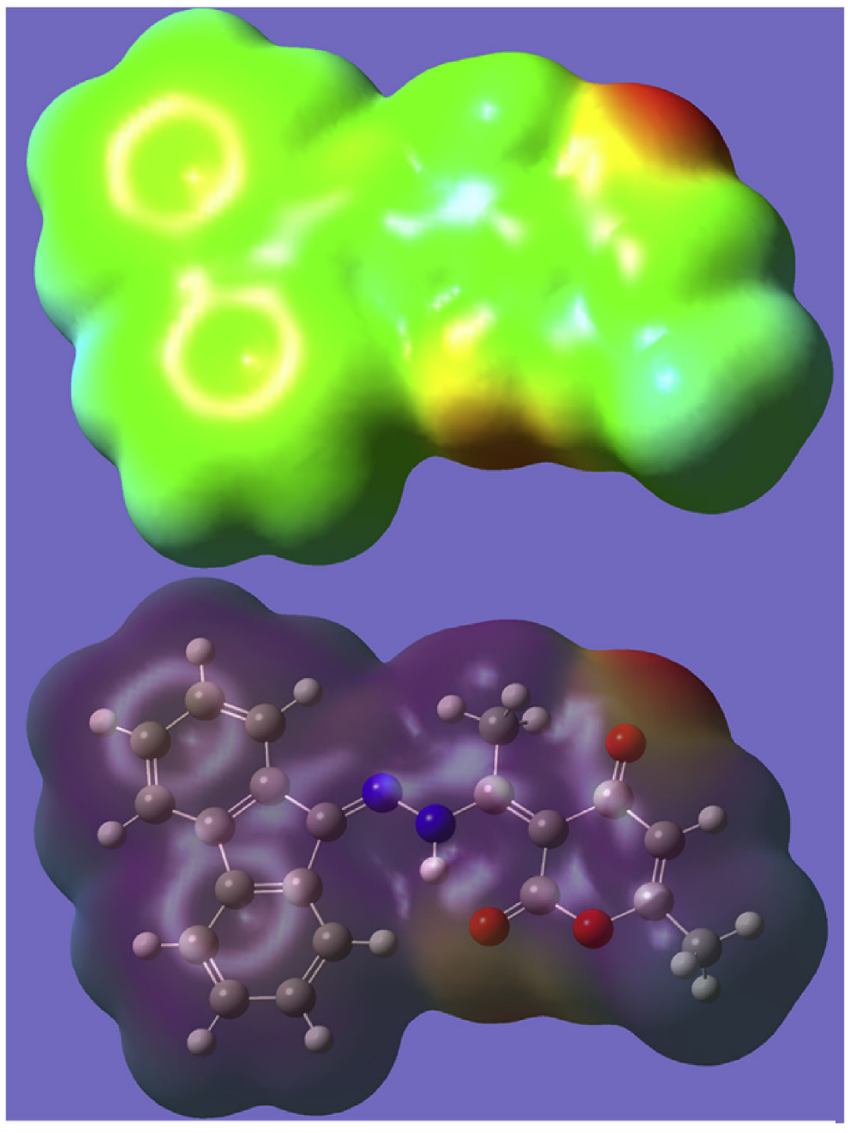

Fig. 5. MEP Map of the desired compound.

\subsection{HAS and MEP computation}

These analyses were performed by using CIF data of the crystal. Intermolecular contacts were figured out by small or big red-spots on surface of the molecule $[16,37,38]$. Since the ligand possesses a number of heteroatoms, $\mathrm{N}$ and $\mathrm{O}$, several polar sets were formed, including nine red-spots on the $d_{\text {norm }}$ molecule surface (Fig. $4 \mathrm{a}-\mathrm{b}$ ). The big spot is cited to the strong intramolecular $\mathrm{O}$....H-N and $\mathrm{H}_{\mathrm{Ph}}$ ... $\mathrm{O}=\mathrm{C}$ hydrogen bond interactions. Notably, the shape index confirmed the $\mathrm{H}-\pi$ and $\pi-\pi$ stacking interactions, which are in a strong agreement with the XRD results (Fig. $4 c-d$ ).

MEP provided valuable information of hydrogen bonding in the molecular structure of compound as well as determining the electrophilic or nucleophilic groups. The DFT/B3LYP method at $6-311++G(d, p)$ as basis sets were employed to evaluate MEP of the new ligand. The results of the computed molecule have revealed potential decreases in the following order: blue $>$ cyan $>$ green $>$ yellow $>$ orange $>$ red. The MEP reflected also the $\mathrm{O}, \mathrm{N}$ and some $\mathrm{C}$ atoms as nucleophilic sites, meanwhile, the hydrogen atoms as electrophilic sites (Fig. 5). Therefore, the possibility of formation of $\mathrm{H}$-bonding is very high. These results are strongly matching with HSA and XRD outcomes.

\subsection{Two-dimensional figure print (2D-FP) investigations}

The 2D-FP analysis supports the presence of intermolecular contacts in the subordinate: $\mathrm{H} \ldots . \mathrm{H}>\mathrm{C} \ldots . \mathrm{H}>\mathrm{O} \ldots \mathrm{H}>\mathrm{N} \cdots \mathrm{H}$, as shown in Fig. 6a-e. The percentage of atom-to-atom finger print intermolecular interactions reflects the $\mathrm{H}$.... $\mathrm{H}$ bonds as a major contributor with $41.8 \%$, while the $\mathrm{N} \cdots \mathrm{H}$ with minor ratio, $0.7 \%$. 

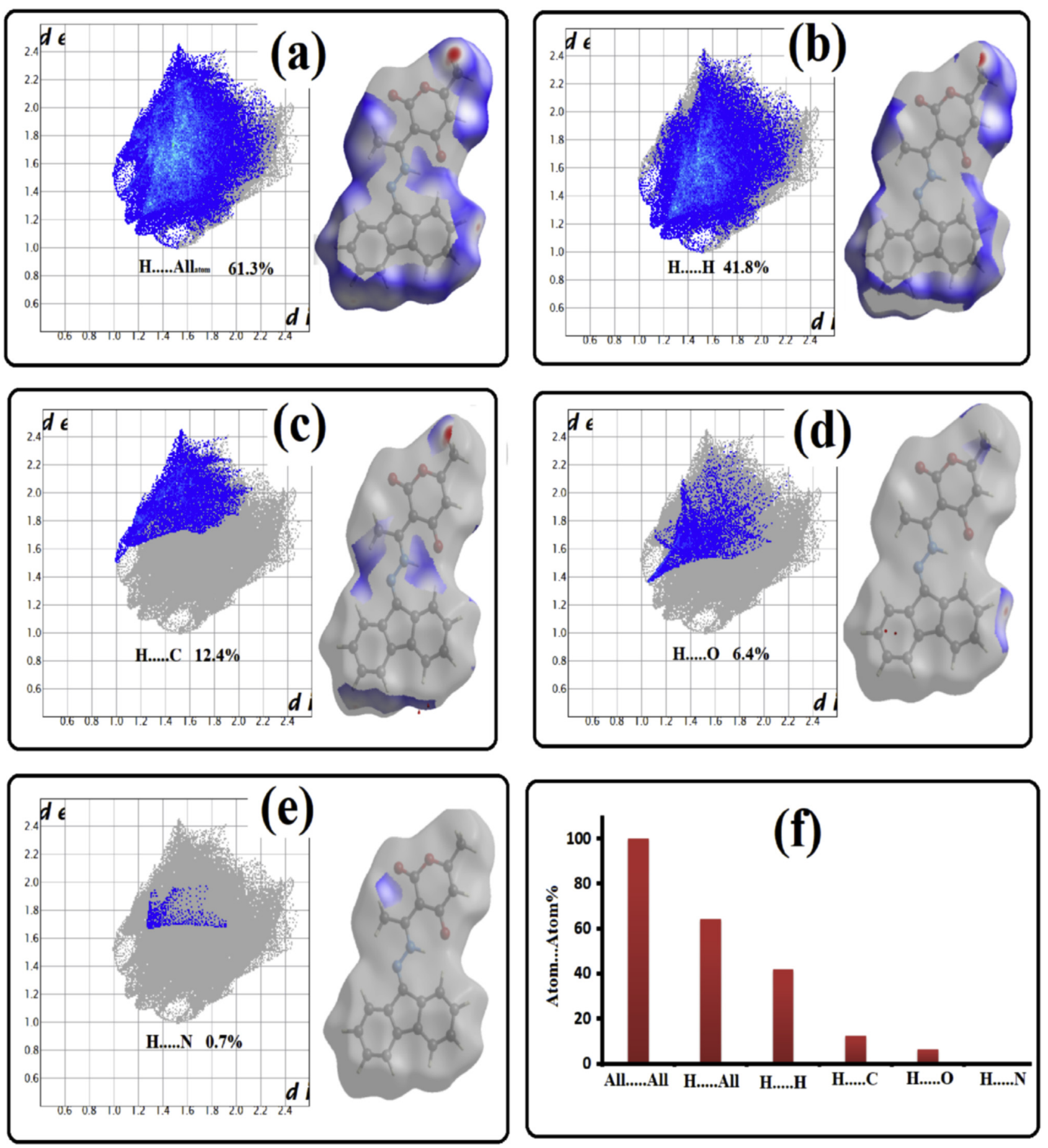

Fig. 6. Atom-to-atom 2D-FP interactions and their contribution ratios.

\subsection{Enol $\leftrightarrow$ hydrazinium prototropic tautomerization}

The gas phase enol $\leftrightarrow$ hydrazinium tautomerization was examined by IRC and DFT/B3LYP/6-311++G (d,p) simulation and the transition state (TS) was optimized via $\mathrm{TS}_{\text {(Bernyl) }}$ method. The experimental and computational of proton transfer mechanism study suggested that the proton of the $\mathrm{OH}$ group, initially created intramolecular hydrogen bond (intraHB) and then moved in space via single proton transfer to the near $N$-atom of $N 2=C 1$ unit in an intra-six-membered ring with $S$ (6) transition state, as demonstrated in Scheme 2. Before the proton leaves the O-atom completely and form the zwitterionic intermediate, the prototropic process includes $\mathrm{O} \cdots \mathrm{H}$ and $\mathrm{N} \cdots \mathrm{H}$ distances of 1.818 and $0.883 \AA$, respectively. The $E_{\mathrm{TS}}$ profiles was found to be $120.2 \mathrm{~kJ} / \mathrm{mol}$, as illustrated in Fig. 7. According to the TS, the structural properties is close to the zwitterionic form, since slightly short $\mathrm{N} \cdots \mathrm{H}$ compared to $\mathrm{O} \cdots \mathrm{H}$ distances was recorded. Such results are in consistence with Hammond postulate and indicating that the $\left[\mathrm{O}^{-} \cdots \mathrm{H}-\mathrm{N}^{+}=\mathrm{C}\right]$ $\mathrm{S}$ (6) ring formation. However, depending on the X-ray result and DFT calculation that clearly reflected the keto form as a more stable 


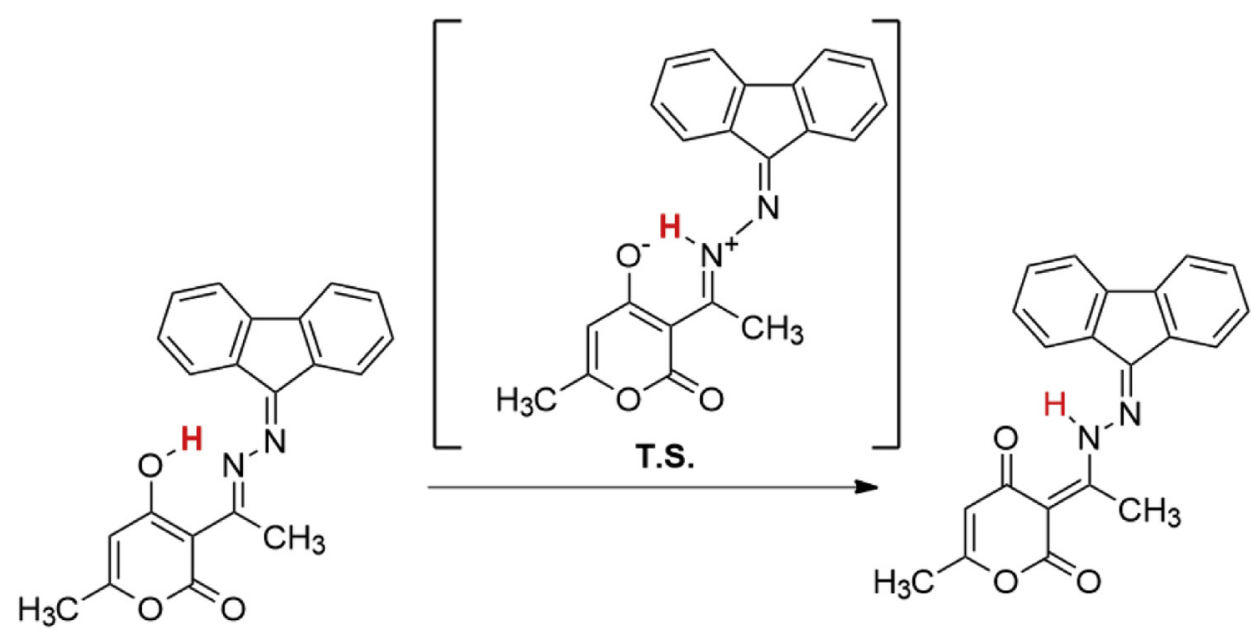

Scheme 2. Prototropic enol $\leftrightarrow$ hydrazinium tautomerism.

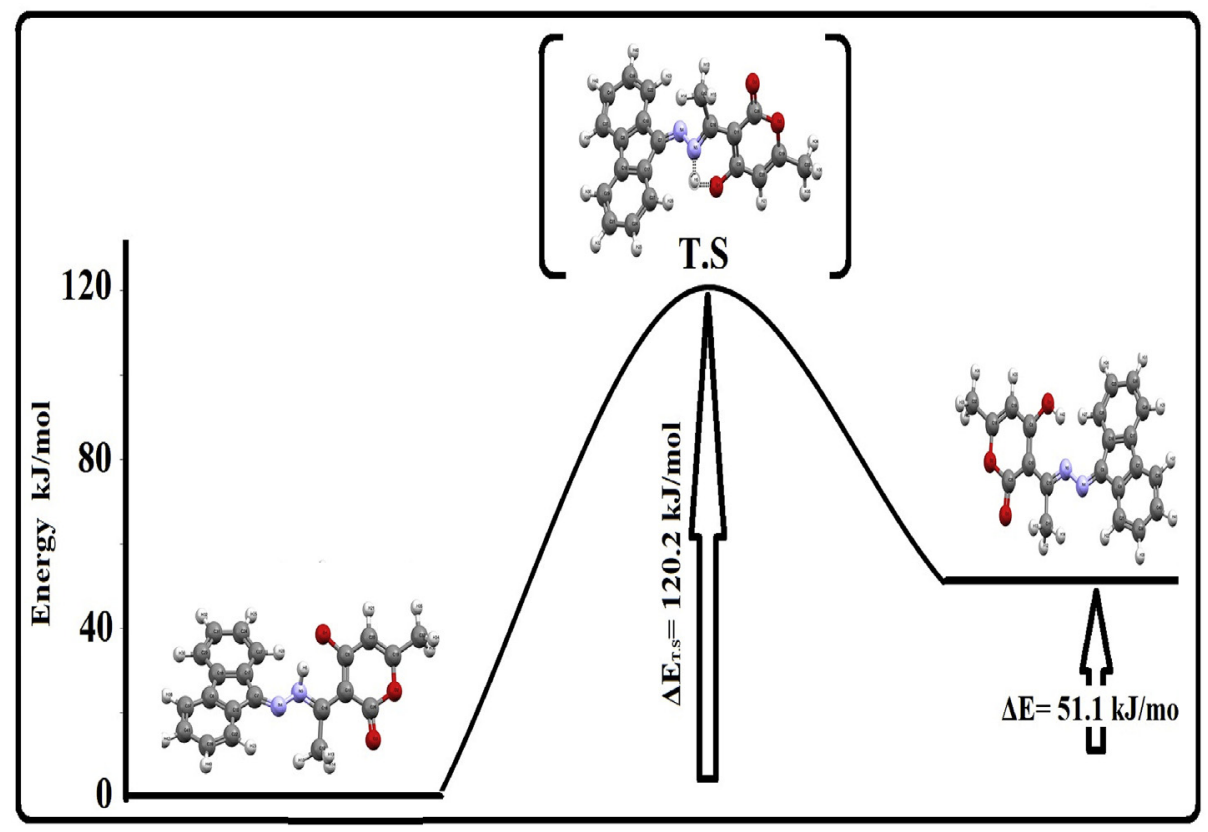

Fig. 7. Prototropic enol $\leftrightarrow$ hydrazinium tautomerism energy profiles.

isomer with zero reference energy and the enol form as a less stable isomer. Nevertheless, DFT energy difference calculation showed the enol with $51.1 \mathrm{~kJ} / \mathrm{mol}$ that destabilized it compared to the keto one, this amount of energy is not so high; therefore, it is possible for example to find both isomers at equilibrium in the liquid state by using suitable polar solvents [3-5].

\section{6. ${ }^{1} \mathrm{H}$ NMR and FT-IR investigations}

The structural formation was further elucidated by FT-IR and ${ }^{1} \mathrm{H}$ NMR spectroscopy. The ${ }^{1} \mathrm{H}$ - NMR in $\mathrm{CDCl}_{3}$ has reflected the anticipated peaks, for instance, the aromatic protons are recorded as a multiplet with chemical shifts in a range of 7.20-7.90 ppm (8H). As expected, the vinylic proton is located at $5.91 \mathrm{ppm}$ as a singlet, while at $9.85 \mathrm{ppm}$, a broad peak designated to $\mathrm{N}-\mathrm{H}$ is assigned. The two-methyl groups are verified at $2.15 \mathrm{ppm}$ and $2.56 \mathrm{ppm}$, the later shift indicates the protons of acetyl group. On the other hand, the recorded FT-IR of the synthesized ligand reflected the obscurity of
$\mathrm{N}-\mathrm{H}$ and/or $\mathrm{O}-\mathrm{H}$ vibrations in a range around $3100-3500 \mathrm{~cm}^{-1}$, that could be rationalized to the enolization process between these two characteristic functional groups. This would strongly confirm the existence of intramolecular $\mathrm{H}$-bond $(\mathrm{C}=\mathrm{O} \cdots \mathrm{H}-\mathrm{N})$ in the solid state of the compound [20-23,31]. Such interaction (intramolecular hydrogen bond) could dramatically influence the appearance of the $\mathrm{C}-\mathrm{H}$ stretching vibrations in the spectrum. A typical strong stretching band of $\mathrm{C}=\mathrm{O}$ is displayed at $1715 \mathrm{~cm}^{-1}$, while sharp $\mathrm{C}=\mathrm{N}$ and $\mathrm{C}=\mathrm{C}$ stretching absorptions are visible at $1653 \mathrm{~cm}^{-1}$ and $1527 \mathrm{~cm}^{-1}$, respectively [39-41], Fig. 8 .

\subsection{Optical activity: HOMO-LUMO, DOS, TD-SCF, UV-Vis. And optical band gap analysis}

The B3LYP HOMO and LUMO surfaces represented the frontier orbitals were performed) Fig. 9). The energy values of such MO orbitals and the energy gap are accurately related to both the electrical transport and optical properties. The $\Delta \mathrm{E}$ calculated from 


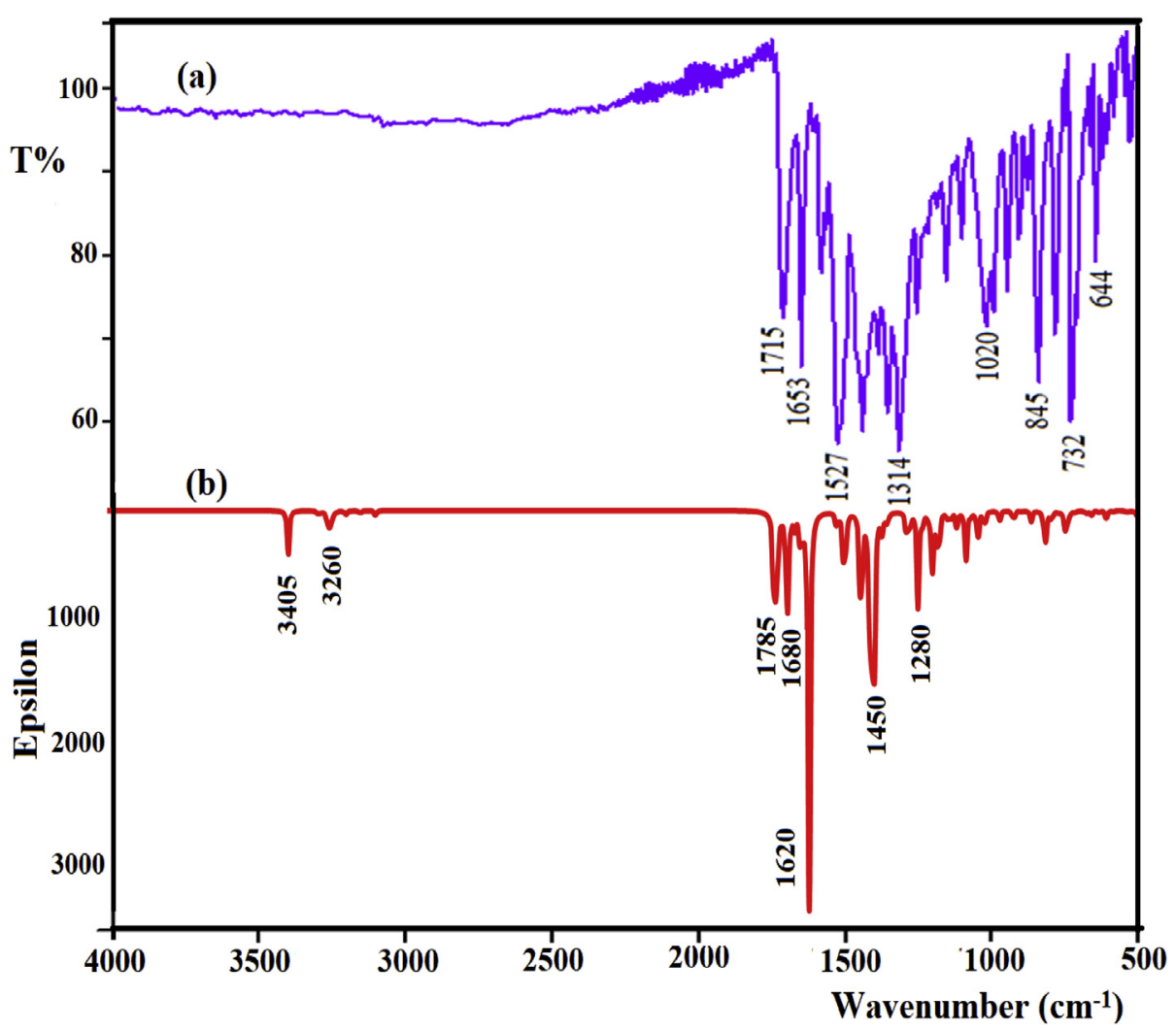

Fig. 8. (a) Exp. Solid state and (b) B3LYP-IR of the synthesized ligand.
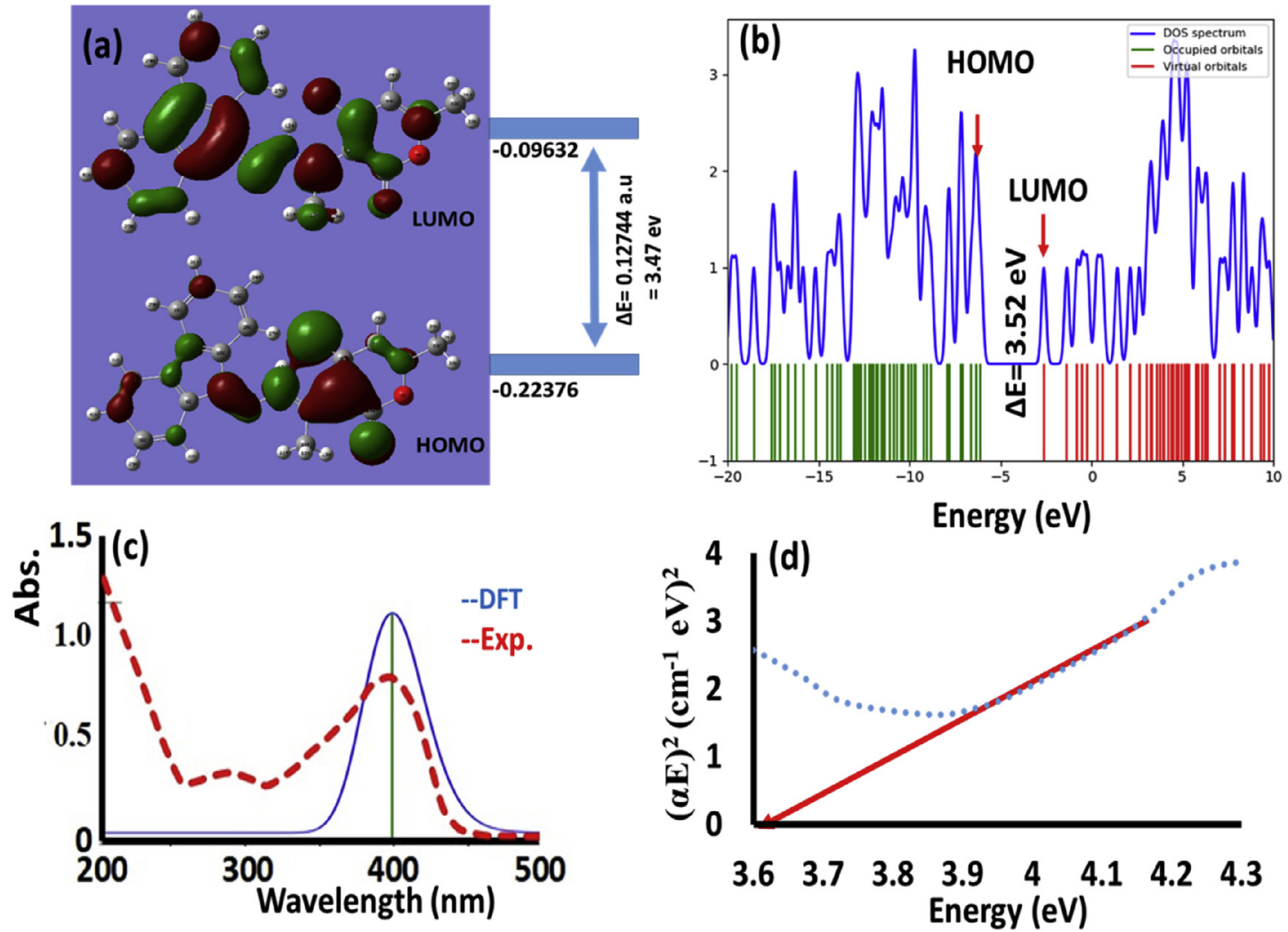

Fig. 9. (a) HOMO/LUMO shape and energy, (b) DOS diagram, (c) UV-Vis/TD-SCF spectroscopy, and (d) Optical band gap of the desired ligand. 
HOMO and LUMO is found to be $3.47 \mathrm{eV}$ (Fig. 9a). The density of state (DOS) and MO contributions calculation especially for HOMO and LUMO as illustrated in Fig. 9b. DOS plot reflected the understandable view of MO and their energies, the population analysis per MO also clearly detected, for example, HOMO is with higher density contribution compare to LUMO, moreover, the DOS energy gap $\Delta \mathrm{E}_{\mathrm{DOS}}$ found to be $3.52 \mathrm{eV}$, which is consistent with the $\Delta_{\mathrm{EHOMO}}$ LUMO value (Fig. 9a). The experimental absorption behavior and TDSCF/B3LYP computation were performed in the DMSO solvent, in order to study and compare the optical behavior and recognize the electronic structure of the desired ligand as seen in Fig. 9c. Two absorption peaks at 290 and $397 \mathrm{~nm}$ were recorded experimentally and can be attributed to $\mathrm{n}$ or $\pi$ to $\pi^{*}$ electron transfer. One broad peak at $400 \mathrm{~nm}$ where detected by TD-DFT due to HOMO $\rightarrow$ LUMO electron transfer (Fig. 9c). The Absorption shift between calculated and experimental is very small ( $3 \mathrm{~nm}$ ) which is commonly observed in TD-DFT/B3LYP calculations [32,33]. The diversity of absorption peaks in the UV band and the absence of the visible region absorption guaranty material to be suitable for optical and photonic applications. The experimental optical band gap for the desired ligand was established by using Tauc's formula [34,42]. In comparison the experimental $\Delta \mathrm{Eg}$ with the simulated $\Delta \mathrm{E}_{\mathrm{HOMO} / \mathrm{LUMO}}$ and $\Delta \mathrm{E}_{\mathrm{DOS}}$, the variation value between $\Delta \mathrm{E}_{\mathrm{HOMO} / \mathrm{LumO}}$ and the experimental $\Delta \mathrm{E}_{\mathrm{g}}$ is $0.14 \mathrm{eV}$. Meanwhile, the variation value between $\Delta \mathrm{E}_{\mathrm{DOS}}$ with $\Delta \mathrm{Eg}$ is $0.09 \mathrm{eV}$. For this reason, the Tauc's equation is a trustable model to figure out the electronic transition to determine the optical activity behavior pure organic compounds.

\section{Conclusions}

The new compound, (E)-3-(1-(2-(9H-fluoren-9-ylidene)hydrazineyl)ethylidene)-6-methyl-2H-pyran-2,4(3H)-dione, was smoothly synthesized via condensation and tautomerazation processes consequently. The enol $\leftrightarrow$ keto tautomerism reaction of functionalized SB derivative was examined to estimate some electronic properties that occurs via single proton shifting from the $\mathrm{OH}$ to the close $\mathrm{N}_{\text {iminium }}$ atom. The XRD and DFT calculations of the target product reflected that the keto form is favored in the solidstate. The existence of heteroatoms in the structure led to a number of short interactions, discovered in the crystal lattice. The theoretically and experimentally the desired compound was confirmed to be optical active only in the UV region.

\section{Declaration of competing interest}

The authors declare that they have no conflicts of interest.

\section{Acknowledgements}

The authors acknowledge the Algerian Directorate General for Scientific Research and Technological Development and the Algerian Ministry of Higher Education and Scientific Research, for support of this work. Researchers Supporting Project (RSP-2020/78), King Saud University, Riyadh, Saudi Arabia.

\section{References}

[1] S. Lochbrunner, C. Schriever, E. Riedle, in: J.T. Hynes, J.P. Klinman, H.-
H. Limbach, R.L. Schowen (Eds.), Hydrogen-Transfer Reactions, Wiley-VCH, Weinheim, Germany, 2006, p. 349.

[2] L. Vilčiauskas, M.E. Tuckerman, G. Bester, S.J. Paddison, K.-D. Kreuer, Nat. Chem. 4 (2012) 461.

[3] R. Daengngern, R. Salaeh, T. Saelee, K. Kerdpol, N. Kungwan, J. Mol. Liq. 286 (2019) 110889.

[4] S. Lochbrunner, in: L. Antonov (Ed.), Tautomerism: Methods and Theories, Wiley-VCH, Weinheim, Germany, 2013, p. 79.

[5] V.I. Tomin, A.P. Demchenko, P.-T. Chou, J. Photoch. Photobio. C 22 (2015) 1.

[6] A.C. Sedgwick, L. Wu, H.-H. Han, S.D. Bull, X.-P. He, T.D. James, J.L. Sessler B.Z. Tang, H. Tian, J. Yoon, Chem. Soc. Rev. 47 (2018) 8842.

[7] W. Al Zoubi, A.A.S. Al-Hamdani, M. Kaseem, Appl. Organomet. Chem. 30 (2016) 810.

[8] M.S. More, P.G. Joshi, Y.K. Mishra, P.K. Khanna, Mater. Today Chem. 14 (2019) 100195.

[9] S. Uzun, Z. Demircioğlu, M. Taşdoğan, E. Ağar, J. Mol. Struct. 1206 (2020) 127749 .

[10] T.M. Krygowski, K. Woźniak, R. Anulewicz, D. Pawlak, W. Kolodziejski, E. Grech, A. Szady, J. Phys. Chem. 101 (1997) 9399.

[11] L. Antonov, W.M.F. Fabian, D. Nedeltcheva, F.S. Kamounah, J. Chem. Soc. Perkin Trans. 2 (2000) 1173.

[12] H. Nazır, M. Yıldız, H. Yılmaz, N. Tahir, D. Ülkü, J. Mol. Struct. 524 (2000) 241.

[13] M. Ziółek, J. Kubicki, A. Maciejewski, R. Naskręcki, A. Grabowska, Phys. Chem. Chem. Phys. 6 (2004) 4682-4689.

[14] J. Jankowska, M.F. Rode, J. Sadlej, A.L. Sobolewski, ChemPhysChem 15 (2014) 1643-1652.

[15] M.R. Aouad, M. Messali, N. Rezki, N. Al-Zaqri, I. Warad, J. Mol. Liq. 264 (2018) 621.

[16] M.R. Aouad, M. Messali, N. Rezki, M.A. Said, D. Lentz, L. Zubaydi, I. Warad, J. Mol. Struct. 1180 (2019) 455.

[17] A.J. Cohen, P. Mori-Sánchez, W. Yang, Chem. Rev. 112 (2012) 289-320.

[18] J.H. Chong, M. Sauer, B.O. Patrick, M.J. MacLachlan, Org. Lett. 5 (2003) 3823.

[19] L. Zhao, Q. Hou, D. Sui, Y. Wang, S. Jiang, Spectrochim. Acta 67 (2007) 1120.

[20] T.B. Hadda, M.A. Ali, V. Masand, S. Gharby T. Fergoug, I. Warad, Med. Chem. Res. 22 (2013) 1438.

[21] I. Warad, Y. Al-Demeri, M. Al-Nuri, S. Shahwan, M. Abdoh, S. Naveen, N.K. Lokanath, M.S. Mubarak, T.B. Hadda, Y.N. Mabkhot, J. Mol. Struct. 1142 (2017) 217.

[22] S. Tabti, A. Djedouani, D. Aggoun, I. Warad, S. Rahmouni, S. Romdhane, H. Fouzi, J. Mol. Struct. 1155 (2018) 11.

[23] I. Warad, M. Abdoh, A. Al Ali, N. Shivalingegowda, K. Kumara, A. Zarrouk, N.K. Lokanath, J. Mol. Struct. 1154 (2018) 619.

[24] A. Djedouani, B. Anak, S. Tabti, F. Cleymand, M. Francoise, S. Fleutot, Acta Crystallogr. E74 (2018) 172.

[25] A.D. Becke, Phys. Rev. A Gen. Phys. 38 (1988) 3098.

[26] C. Lee, W. Yang, R.G. Parr, Phys. Rev. B Condens. Matter 37 (1988) 785.

[27] T.A. Mohamed, U.A. Soliman, I.A. Shaaban, W.M. Zoghaib, L.D. Wilson, J. Mol. Struct. 1207 (2020) 127837.

[28] T.A. Mohamed, U.A. Soliman, I.A. Shaaban, W.M. Zoghaib, L.D. Wilson, Spectrochim. Acta 150 (2015) 339.

[29] Rigaku Oxford Diffraction, CrysAlisPro Software System, Rigaku Corporation, Oxford, UK, 2018 version 1.171.39.46.

[30] G.M. Sheldrick, Acta Crystallogr. A71 (2015) 3.

[31] O.V. Dolomanov, L.J. Bourhis, R.J. Gildea, J.A.K. Howard, H. Puschmann, J. Appl. Crystallogr. 42 (2009) 153.

[32] G.M. Sheldrick, Acta Crystallogr. C71 (2015) 3.

[33] M.J. Frisch, G.W. Trucks, H.B. Schlegel, G.E. Scuseria, et al., Gaussian 09W Gaussian Inc., Wallingford CT, 2009.

[34] R. Dennington, T. Keith, J. Millam, Gauss View Version 5, Semichem Inc., Shawnee Mission, 2009.

[35] S.K. Wolff, D.J. Grimwood, J.J. McKinnon, M.J. Turner, D. Jayatilaka, M.A. Spackman, Crystal Explorer 3.0, University of Western Australia, Perth, 2012.

[36] C.R. Martinez, B.L. Iverson, Chem. Sci. 3 (2012) 2191.

[37] T.A. Mohamed, A.M. Hassan, U.A. Soliman, W.M. Zoghaib, J. Husband, M.M. Abdelall, J. Mol. Struct. 985 (2011) 277.

[38] A. Barakat, M.S. Islam, A.M. Al-Majid, H.A. Ghabbour, S. Atef, A. Zarrouk, I. Warad, J. Theor. Comput. Chem. 17 (2018) 1850005.

[39] I. Warad, F.F. Awwadi, B. Abd Al-Ghani, A. Sawafta, N. Shivalingegowda, N.K. Lokanath, M.S. Mubarak, T. Ben Hadda, A. Zarrouk, F. Al-Rimawi, A.B. Odeh, S.A. Barghouthi, Ultrason. Sonochem. 48 (2018) 1.

[40] U.A. Soliman, J. Struct. Chem. 57 (2016) 76.

[41] C.R. Martinez, B.L. Iverson, Chem. Sci. 3 (2012) 2191.

[42] J. Tauc, A. Menth, J. Non-Cryst. Solids 8 (1972) 569. 